\title{
Microencapsulación de compuestos de actividad biológica
}

\author{
Lopretti, M. ${ }^{(1)(4)}$; Barreiro, $\mathbf{F}^{(2)}$; Fernandes, $\mathbf{I}^{(2)}$; Damboriarena, A. ${ }^{(1)}$; Ottati, $\mathbf{C}^{(1)}$; Olivera, A ${ }^{(3)}$ \\ Contacto: mlopre@latu.org.uy \\ (1) Departamento de Bioprocesos y Biotecnología - Laboratorio Tecnológico del Uruguay (LATU) \\ (2) Instituto Politécnico de Bragança- Portugal \\ (3) Unidad de Microscopía Electrónica de Transmisión- Facultad de Ciencias -UdelaR \\ (4) Laboratorio de Bioquímica y Biotecnología - CIN- Facultad de Ciencias- UdelaR
}

\begin{abstract}
Resumen
La microencapsulación de compuestos de actividad biológica (ADN, fármacos, proteínas, probióticos, enzimas, etc.), desde el punto de vista tecnológico, podría definirse como el proceso de recubrimiento de dichos compuestos, bajo la forma de moléculas, partículas sólidas o glóbulos líquidos, con materiales de distinta naturaleza, para dar lugar a partículas de tamaño micrométrico. Uno de los polímeros naturales más utilizados para la producción de microesferas es el quitosano ( $\beta$-1,4- glucosamina).

Diversos métodos han sido propuestos para la producción de microcápsulas, divididos en tres grupos: procesos físicos, procesos químicos y procesos físico-químicos.

En el presente trabajo se ensayaron distintas metodologías para la producción de microesferas y microcápsulas de quitosano. Según la metodología empleada se obtuvieron distintos tipos de esferas en lo que respecta a tamaño y densidad principalmente. Las micropartículas obtenidas se evaluaron mediante microscopía óptica, electrónica de barrido, así como se realizó la evaluación de su estabilidad y liberación del agente encapsulado.
\end{abstract}

\begin{abstract}
The microencapsulation process of agents with biological activity (such as DNA, pharmaceuticals, proteins, probiotics, enzymes, etc.), from the technological view, could be defined as the coating process of those agents, under a molecular form, solid particles, or liquid globules, with materials of different nature, that gives particles particles of micrometric size. One of the most used natural polymers for the production of microspheres is chitosan ( $\beta-1,4-$ glucosamine).

Various methods have been proposed for the production of microcapsules, divided into three groups: physical processes, chemical processes, and physico-chemical processes.

In this work, it were assayed different methodologies for the production of chitosan microspheres and microcapsules. Depending on the methodology used, were obtained differente types of spheres in reference to size and density. The microparticles produced were evaluated with optic microscopy, scanning electronic microscopy, so as were evaluated its stability and liberation of the encapsulated agent.
\end{abstract}

Palabras clave: microencapsulación, microesferas, microcápsulas, quitosano, polímero, poliuretano, biodegradable.

\section{Generalidades de la microencapsulación}

$\mathrm{L}$ os procesos de encapsulación fueron desarrollados entre los años 1930 y 1940 por la National Cash Register para la aplicación comercial de un tinte a partir de gelatina como agente encapsulante mediante un proceso de coacervación (Popplewell et.al. 1995)

La microencapsulación de compuestos de actividad biológica (ADN, fármacos, proteínas, probióticos, enzimas, etc.), desde el punto de vista tecnológico, podría definirse como el proceso de recubrimiento de dichos compuestos, bajo la forma de moléculas, partículas sólidas o glóbulos líquidos, con materiales de distinta naturaleza, para dar lugar a partículas de tamaño micrométrico. El producto resultante de este proceso tecnológico recibe la denominación de "microesfera" ó "microcápsula", dependiendo de cual sea su morfología y estructura interna.

Las microcápsulas se diferencian de las microesferas principalmente por el tipo de estructura interna (Figura 1). En el primer caso, el principio activo, que puede ser de naturaleza líquida o sólida, se encuentra incluido en una especie de reservorio recubierto por una fina película de material. En el caso de las microesferas, el principio activo se encuentra altamente disperso bajo la forma de diminutas partículas o de moléculas en una matriz de material que puede ser lo mismo del recubrimiento. La obtención de un tipo de estructura u otro, depende de las propiedades fisicoquímicas del principio activo y del material de recubrimiento, así como del proceso tecnológico elegido.

En cuanto al recubrimiento, el polímero utilizado para la constitución, tanto de la microesfera como de la microcápsula, puede ser de origen natural como sintético (Aitex Review). Uno de los polímeros naturales utilizados para la producción de microesferas es el quitosano ( $\beta$-1,4- glucosamina). Éste biopolímero policatiónico, es la forma soluble (desacetilada) de la quitina, un polímero lineal constituido por residuos de $\mathrm{N}$-acetilglucosamina, presente en el exoesqueleto de los crustáceos, por ejemplo el camarón.

Los principales parámetros que influyen en las características del quitosano son, su peso molecular y el grado de desacetilación, representando la porción de unidades desacetiladas. Estos parámetros, son determinados por las condiciones de reacción durante el proceso de preparación del quitosano (Varshosaz 2005).
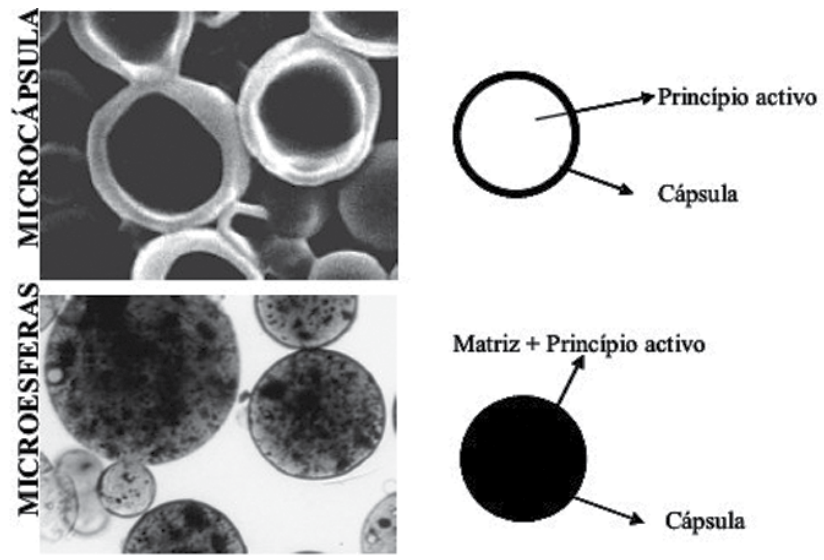

Figura 1. Microesferas versus microcápsulas 
Por otro lado, existe la posibilidad de utilizar un polímero sintético, como el poliuretano que se puede formar in situ por un proceso designado por polimerización interfacial. La síntesis de los poliuretanos es basada en la química de lo grupo isocianato que puede reaccionar con los grupos hidroxilo (formando lo grupo uretano) o conducir a un conjunto de reacciones secundarias conforme representado en la Figura 3 .

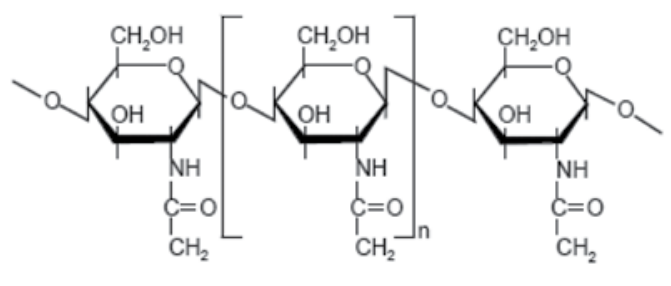

(a)

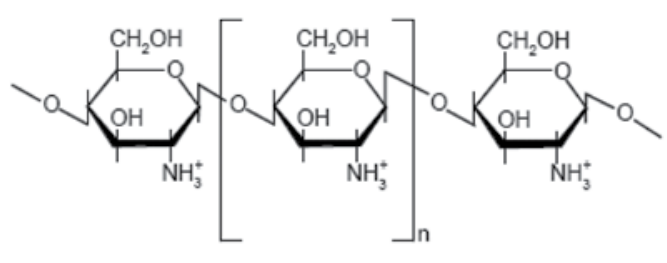

Chitosan

(b)

Figura2. Esquema de la estructura de la quitina (a) y del quitosano (b)

$$
\begin{aligned}
& \text { Formación del grupo uretano } \\
& \mathrm{R}-\mathrm{NCO}+\mathrm{HO}-\mathrm{R}^{\prime} \longrightarrow \text { ALCOHOL }
\end{aligned}
$$

\section{Reacciones secundarias}

$$
\begin{aligned}
& \mathrm{R}-\mathrm{NCO}+\mathrm{H}_{2} \mathrm{~N}-\mathrm{R}^{\prime} \longrightarrow \mathrm{R}-\mathrm{N}^{\prime}-\mathrm{N}_{\mathrm{N}}-\mathrm{R}^{\prime} \text { UREIS }
\end{aligned}
$$

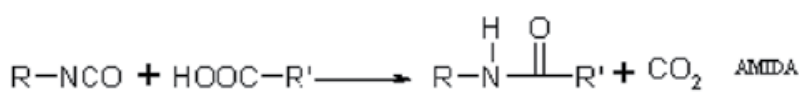

$$
\begin{aligned}
& \text { ACDDO CARBOXHIICO } \\
& \mathrm{R}-\mathrm{NCO}+\mathrm{H}_{2} \mathrm{O} \longrightarrow \mathrm{R}-\stackrel{\mathrm{N}}{\mathrm{H}} \stackrel{\mathrm{O}}{\mathrm{O}} \\
& \mathrm{H}_{2} \mathrm{~N}-\mathrm{R}+\mathrm{CO}_{2}
\end{aligned}
$$

Figura 3. Ejemplo de formación de polímero sintético. Esquema de la reacción de formación del uretano y reacciones secundarias en la formación del grupo isocianato.

Diversos métodos han sido propuestos para la producción de microcápsulas. En general, estos métodos pueden ser divididos en tres grupos: procesos físicos, procesos químicos y procesos físico-químicos, como se comentará más adelante.

\begin{tabular}{|c|c|c|}
\hline $\begin{array}{c}\text { POLÍMEROS } \\
\text { BIODEGRADABLES }\end{array}$ & $\begin{array}{c}\text { POLÍMEROS } \\
\text { BIOCOMPATIBLES }\end{array}$ & $\begin{array}{l}\text { OTROS POLÍMEROS } \\
\text { SINTÉTICOS }\end{array}$ \\
\hline $\begin{array}{l}\text { Polilácticos (PLA) } \\
\text { Poligícolicos (PGA) } \\
\text { Copolímeros lácticlo- } \\
\text { glicólico (PLG) } \\
\text { Policaprolactona (PCL) } \\
\text { Polyhydroxybutyrate } \\
\text { Poliortoésteres } \\
\text { Proteínas (albúmina, } \\
\text { colágeno, gelatina) } \\
\text { Polisacáridos } \\
\text { (dextranos } \\
\text { Quitina/Quitosano) }\end{array}$ & $\begin{array}{l}\text { Polímeros acrílicos y } \\
\text { copolímeros (Etilen } \\
\text { glicol dimetacrilato, } \\
\text { acrilamida, bis- } \\
\text { acrilamida ) } \\
\text { Polímeros celulósicos } \\
\text { Polímeros de } \\
\text { etilenglicol y } \\
\text { copolímeros } \\
\text { Polímeros de oxietilen } \\
\text { y oxipropilen } \\
\text { Polivinil alcohol y } \\
\text { polivinilacetato } \\
\text { Polivinilpirrolidina y } \\
\text { polivinilpiridina }\end{array}$ & $\begin{array}{l}\text { Poliuretano } \\
\text { Poliurea } \\
\text { Poliamidas } \\
\text { Resinas fenol- } \\
\text { formaldehído } \\
\text { Resinas melanina- } \\
\text { formaldehído }\end{array}$ \\
\hline
\end{tabular}

Un hecho destacable del proceso de microencapsulación radica en que su aplicación no se limita únicamente al campo de las sustancias biológicas ó medicamentos, sino que se extiende a campos tan diversos como la agricultura, la cosmética y la alimentación, así como a diversas áreas industriales.
Tabla 1: Principales tipos de polímeros utilizados para la producción tanto de microesferas como de microcápsulas.

La utilización de microcápsulas o microesferas, abarca una amplia gama de campos: la eliminación controlada de sabores, colores, aromas, perfumes, drogas, fertilizantes, etc. Las enzimas y las células animales o vegetales también pueden ser encapsuladas, permitiendo que los sustratos y productos entren y salgan de la cápsula. Este concepto fue instrumentado con el desarrollo de un hígado artificial con enzimas hepáticas colocadas en membranas semipermeables para mejorar su función. Las membranas de nylon han sido empleadas para encapsular y atrapar enzimas como la pepsina, la pectin esterasa para clarificación de jugos, la invertasa para la inversión de sacarosa y la renina para coagulación de leche. Una bacteria ácido láctica, Lactobacillus lactis, fue encapsulada en alginato y se sugiere que las bacterias inmovilizadas pueden ser usadas para producir yogurt de manera continua (Yañez Fernández et.al. 2002).

\section{Principales técnicas de microencapsulación}

$\mathrm{T}$ anto la producción de microesferas como de microcápsulas, involucra procesos de distinta naturaleza según sea el objetivo. Dichos procesos productivos, se pueden agrupar en tres grandes categorías, como se observa en la Tabla 2.

\section{PROCESOS FISICOS}

Secado por aspersión

Extrusión

Recubrimiento por aspersión

PROCESOS QUIMIICOS

Coacervación simple

Coacervación compleja

Atrapamiento en liposomas

PROCESOS FISICO-QUIMIICOS

Polimerización interfacial

Inclusión molecular

Tabla 2: Principales métodos para la producción de microesferas ó microcápsulas agrupados según la naturaleza del proceso involucrado (ATIEX Review). 
La elección de una u otra técnica, depende de variables tales como el tamaño deseado de la partícula, la sustancia a encapsular, el tipo de polímero, así como sus aplicaciones y su costo de producción.

Existen dos principales técnicas de emulsión, que permiten llevar a cabo los diferentes procesos de microencapsulación, siendo la emulsión aceite en agua (o/w), y agua en aceite (w/o). En la primera, la emulsión aceite en agua $(\mathrm{o} / \mathrm{w})$, la fase orgánica (fase dispersa) que contiene el polímero y el compuesto a encapsular, se emulsifica en una fase acuosa (fase continua) que contiene el tensoactivo. Posteriormente, las gotas orgánicas emulsificadas son endurecidas por la adición de un agente entrecruzante.

En el caso de la emulsión agua en aceite (w/o), la fase acuosa (fase dispersa) contiene el polímero y el compuesto a encapsular, la cual se emulsifica en una fase orgánica (fase continua) que contiene el tensoactivo, por ejemplo Span 80. Los procesos descritos son validos cuando el objetivo es producir microesferas. Cuando se hacen microcápsulas el material de la cápsula tiene que ser compatible con la fase continua y el principio activo con la fase dispersa.

Utilizando alguna de las técnicas de emulsión descritas, el secado por aspersión es un método ampliamente utilizado en la industria alimenticia, ya que es un método efectivo y económico para la protección de materiales. La técnica se basa en la utilización de carriers (ejemplo, maltodextrinas, goma, almidones modificados) y su homogenización con el material a encapsular. La mezcla luego se introduce en un secador por aspersión, dentro del cual circula aire caliente $\left(150\right.$ a $\left.200{ }^{\circ} \mathrm{C}\right)$ capaz de suministrar la temperatura de vaporización necesaria para eliminar el disolvente del material de cubierta, con lo que se obtiene el producto microencapsulado (Ré 1998, Chiappetta 2007).

Dentro de los procesos físico-químicos, el atrapamiento por liposomas y la coacervación, son dos técnicas ampliamente utilizadas para la microencapsulación de compuestos. Los liposomas, han sido utilizados principalmente para la liberación de vacunas, enzimas y vitaminas en el cuerpo, y consisten de una o más capas de lípidos no tóxicos y aceptables en alimentos; la permeabilidad, estabilidad, actividad superficial y afinidad pueden variar con el tamaño y la composición del lípido. Los liposomas son vesículas que se forman cuando películas de fosfolípidos son dispersadas en un medio acuoso, el cual contiene la sustancia a encapsular.

Los liposomas pueden ser obtenidos con cargas positivas por la adición de aminas o con cargas negativas por la adición de fosfatidil serina o diacetil fosfato (Yañez Fernández et.al. 2002). La liberación del principio activo se realiza por difusión a través de la bicapa, por destrucción de la vesícula, por medio de una concentración crítica de iones calcio o por un cambio de $\mathrm{pH}$.

Por otro lado, bajo la denominación de "coacervación" ó separación de fases, se agrupan una serie de técnicas de microencapsulación que se basan en la inducción por algún procedimiento, de la desolvatación del polímero, que a continuación, se deposita en forma de gotículas de coacervado alrededor del compuesto que se va a encapsular. Entre los procedimientos inductores de la coacervación se puede destacar un cambio en la temperatura, una modificación del pH, y la adición de un "no solvente", una sal o un polímero incompatible. La coacervación puede ser en fase acuosa o en fase orgánica. La coacervación en fase acuosa, implica la utilización de agua como disolvente y un polímero soluble en la misma como material de recubrimiento, y permite la encapsulación de compuestos insolubles en dicho líquido. El compuesto es dispersado directamente en la solución polimérica o en un aceite, que a su vez, es emulsificado en la solución polimérica. Este tipo de coacervación puede ser simple o compleja, dependiendo principalmente de la cantidad de polímeros utilizados. En el caso de una coacervación acuosa simple, se utiliza un único polímero para formar la cápsula, mientras que en la compleja, el proceso de separación de fases tiene lugar de forma espontánea cuando en un medio acuoso se mezclan dos o más polímeros que presentan cargas opuestas (policatión y polianión), como consecuencia de la atracción electroestática que sufren. Por otro lado, la coacervación en fase orgánica, utiliza polímeros solubles en disolventes orgánicos, entre los que se destacan la etilcelulosa y los polímeros de la familia del poliácido láctico. El polímero se disuelve bajo determinadas condiciones en un disolvente orgánico de naturaleza apolar y el material que se va a encapsular se suspende o emulsifica en la solución polimérica. A continuación, por un procedimiento determinado se produce la desolvatación del polímero que se deposita alrededor del núcleo (Chiappetta 2007).

Por último, un ejemplo de proceso químico es la polimerización interfacial. La polimerización interfacial ocurre entre monómeros disueltos en dos fases inmiscibles. En la interfase se desarrolla un proceso de polimerización que da lugar a la formación de microcápsulas (Yañez Fernández et.al. 2002).

\section{Metodología de encapsulación de aromas por diferentes métodos}

\section{A) Producción de microesferas de quitosano con posterior inco- poración de aromas ${ }^{1}$}

La formación de microesferas de quitosano, se realiza según la técnica de emulsión agua-aceite (W/O). Como fase dispersa, se prepara una solución de quitosano al 3,0\% (W/V) en ácido acético al 5\%, siendo posteriormente filtrada. Como fase continua, se utiliza aceite de girasol en un matraz y se le adiciona Span 80. Luego, se agrega la solución de Quitosano 3,0\% por goteo sobre el aceite, en agitación constante a $40{ }^{\circ} \mathrm{C}$.

Posteriormente, se adiciona el Glutaraldehído $25 \%$ (V/V) a los 15 , 30,35 y 60 minutos posteriores al agregado del quitosano, manteniendo la agitación.

Una vez finalizado el agregado del Glutaraldehído, se mantiene la agitación durante un par de horas, para luego decantar las microesferas a temperatura ambiente.

Se descarta el aceite y se realizan sucesivos lavados con éter de petróleo. Se dejan secar a temperatura ambiente.

La incorporación del limoneno, se realiza tomando una cantidad determinada de microesferas, e incubándolas a temperatura ambiente, con una solución de limoneno:aceite.

\section{B) Producción de microcápsulas de quitosano conteniendo limoneno $^{2}$}

Existe la posibilidad de formar microcápsulas de quitosano que contengan lo aroma en el interior. Lo proceso pasa por etapas sucesivas, la primera de las cuales involucra la formación de una emulsión aceite-agua $(\mathrm{O} / \mathrm{W})$. La formulación utilizada se presenta en la figura 4 , así como lo esquema de la fase de reticulación con glutaraldehído.

Se utiliza como fase acuosa, una solución de lecitina al 1\%, mientras que como fase orgánica se utiliza una solución de limoneno (principio activo). Paralelamente, se prepara una solución de quitosano al $2 \%$ en ácido acético al $10 \%$.

En un vaso de bohemia, se coloca la fase orgánica y la fase acuosa (Figura 5). La mezcla se agita a alta velocidad durante un cierto tiempo. Posteriormente se adiciona la solución de quitosano al $2 \%$, modificando la agitación a baja velocidad y se ajusta el pH a 6.0 con $\mathrm{NaOH}$, manteniéndose la agitación. Luego, se añade el glutaraldehído al $25 \%$ y la mezcla se mantiene 2 horas en agitación, para luego dejar decantar las microesferas y lavarlas.

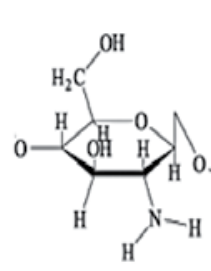

(a)

FO/FA $=0.3$

$(\mathbf{F O}+\mathbf{F A}) / \mathrm{FQ}=2$

$(\mathbf{5 0}+\mathbf{1 7 0}) / \mathrm{FQ}=\mathbf{2}$

Entonces sol $Q=110 \mathrm{ml}$

Sol Q w/w 2\% en ácido acético $10 \%$

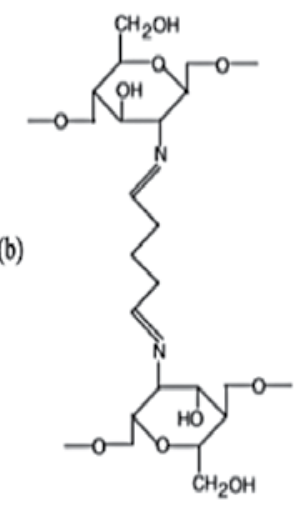

Figura 4: (der) Diagrama de reacción de reticulación (a) quitosano y (b) quitosano reticulado (izq) Relación de fases calculada en base a la reacción de reticulación entre dos moléculas de quitosano por cada molécula de glutaraldehído. (FA) = Fase acuosa, (FO) = Fase orgánica, (FQ) = Fase quitosano. 

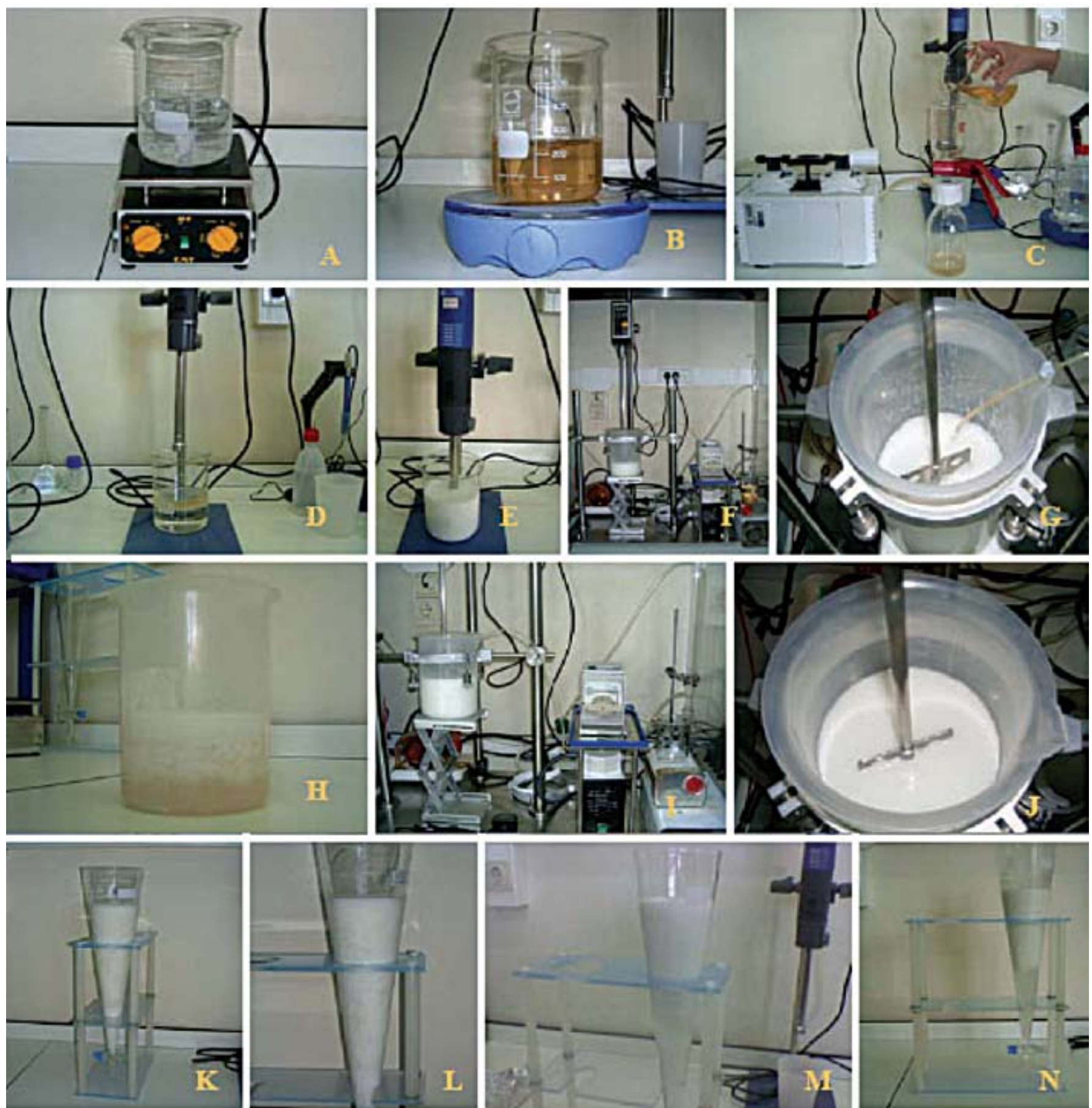

Figura 5. Fases del proceso de síntesis: Preparación de la emulsión (A-E), Precipitación del quitosano (F-H), Reticulación (I-J) e Separación/Lavado (K-N)

\section{Caracterización de las microesferas de quitosano y microcápsulas de poliuretano}

De las esferas obtenidas, se pueden realizar algunos estudios, como:

a) Microscopía Óptica

b) Microscopía Electrónica de Barrido (MEB)

c) Microscopía Confocal de Barrido Láser

d) Relacionamiento de fases

e) Relación de entrecruzamiento

f) Estabilidad y la liberación del agente encapsulado.

En el caso de este último estudio, se incubó una cantidad determinada de microesferas a $4{ }^{\circ} \mathrm{C}$ y $37^{\circ} \mathrm{C}$ en condiciones de $\mathrm{pH} 3,6$ y 9 . El seguimiento se llevó a cabo midiendo la absorbancia del sobrenadante a $325 \mathrm{~nm}$ a lo largo de varios días..

\section{Resultados y discusión}

Producción de microesferas de quitosano con posterior incorporación de aromas

Mediante la metodología descrita para la producción de microesferas, se pudieron obtener esferas sólidas en el orden de $2 \mu \mathrm{m}$ a $30 \mu \mathrm{m}$, dependiendo de la velocidad de agitación.

Por microscopía óptica se observan gran cantidad de partículas discretas y clusters. Se ha observado variación de estas presentaciones, dependiendo de los pasos empleados en el lavado, filtrado y secado de las mismas (Figura 5C).

En MEB, se observan como partículas de forma esférica bien definida, de superficie homogénea y compacta (Figuras 5F, 5G, y 5I). A gran magnificación es posible distinguir leves ondulaciones de la superficie y algunas protuberancias (Figura 5I). La estructura interna se observa compacta (Figura $5 \mathrm{H}$ ) 


\section{Estabilidad y liberación del agente encapsulado}

La estabilidad y liberación del agente encapsulado fue analizada como se describió anteriormente.

En lo que respecta a las microesferas de quitosano conteniendo limoneno, se observó que a $\mathrm{pH} 3$, las mismas son estables y las concentraciones de limoneno presentes en el sobrenadante se mantienen constantes. Probablemente la configuración obtenida del polímero, relacionado con el componente encapsulado bajo estas condiciones, sea responsable de este comportamiento invariante y esto se deba a una rápida desorción de la sustancia aromática presente en la superficie.

A pH neutro se observa un comportamiento dependiente de la temperatura. A $4^{\circ} \mathrm{C}$ se observa una liberación progresiva del componente adsorbido. A $37^{\circ} \mathrm{C}$, se detecta una rápida liberación del componente adsorbido, seguido de una disminución de la concentración del componente en el sobrenadante, posiblemente debido a la recaptación de la sustancia aromática.

Finalmente a $\mathrm{pH} 9$, para ambas condiciones de temperatura, se detecta al igual que a $\mathrm{pH}$ neutro a $37^{\circ} \mathrm{C}$, una rápida liberación de la sustancia, seguido de una disminución de la concentración de la misma en el sobrenadante.

\section{Producción de microcápsulas de quitosano incorpo- rando limoneno en el mismo proceso de formación}

Esta técnica de formación de microcápsulas de quitosano incorporando limoneno, ha utilizado lecitina como fase acuosa. El objeto de su uso ha sido evaluar dicha molécula en comparación con otras similares.
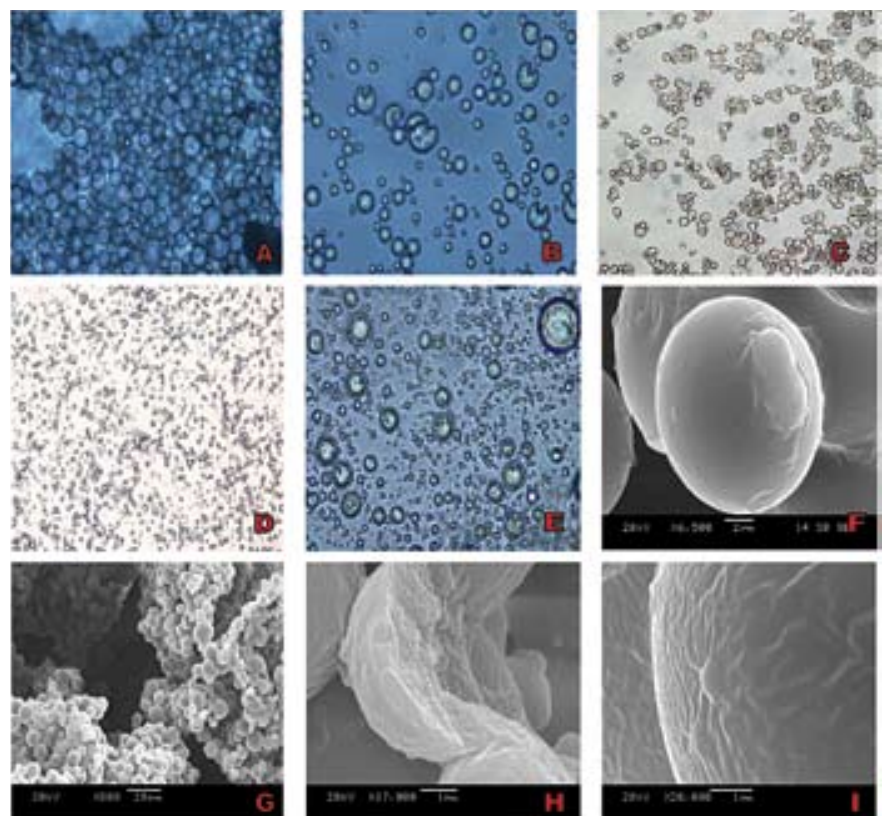

Figura 6: Micrografías de las microesferas de quitosano y microcápsulas de poliuretano. A) Micrografía de microscopía óptica (MO) de microcápsulas de poliuretano - x400. (Portugal) B) Micrografía de MO de microcápsulas de poliuretano - x400. (Portugal) C) Micrografía de MO de microesferas de quitosano - x100. D) Micrografía de MO de microesferas de quitosano - x100 (Portugal). E) Micrografía de MO de microesferas de quitsano - x400 (Portugal). F) Micrografía de Microscopía Electrónica de Barrido (MEB) de microesfera de quitosano - $x 6500 \mathrm{G}$ ) Micrografía de MEB de microesferas de quitosano $-\mathbf{x} 800$.
Se obtuvieron microcápsulas de quitosano, visualizándose el entorno de las mismas cuando se observan al microscopio (ver Figura $6 \mathrm{D}$ y $6 \mathrm{E})$.

\section{Conclusiones}

$\mathrm{D}$ entro de las evaluaciones realizadas de diversas formas de producción de microcápsulas y microesferas, se puede llegar a concluir como tema fundamental el de la relación existente entre la fase acuosa y la fase orgánica, al igual que la concentración de agente entrecruzante que se utiliza, el cual debe estar presente en la cantidad necesaria para que reaccione todo, y no entrecruce entre esferas o cápsulas.

Se han probado distintos sistemas para una misma molécula encapsulada, siendo el principal objetivo entender los efectos fisicoquímicos de las mismas, para la utilización de polímeros naturales que son biocompatibles.

La sustitución de agentes entrecruzantes como el glutaraldehído y el paraformaldehído, es uno de los principales focos de estudios futuros para aumentar la biocompatibilidad del producto.

Por otro lado, las esferas de quitosano son más biocompatibles para otras aplicaciones, pero de las experiencias realizadas hasta el momento presentan menor resistencia.

Creemos de gran interés el uso de las microesferas y microcápsulas, según lo trabajado en el sistema y estudiando diferentes compatibilidades con biomoléculas como ADN, células, plásmidos, etc., como sistemas de protección y liberación controlada.

Este trabajo fue realizado en el marco del Proyecto Producción de microcápsulas - Biotecnología (dentro del proyecto Biotecnología en textiles)

\section{Referencias}

AITEX. Departamento de I+D+I. 2003. Microencapsulación: Nuevas capacidades para los tejidos tradicionales. En: AITEX Review. (julio):1415

Chiappetta, D. 2007. Microencapsulación de medicamentos. Disponible en: http://www.ffyb.uba.ar/farmacotecnia\%20I/Microencapsulacion.htm

Olivera, A.; Lopretti, M.; Damboriarena, A.; Ottati, C. 2007. Producción de microesferas de quitosano para su utilización como carriers de agentes bioquímicos de interés para la industria y la medicina. Presentado en: Jornadas de la Sociedad Uruguaya de Biociencias (12 : 2007 setiembre 2830 : Minas)

Popplewell, L.M.; Black, J.M.; Norris, LM.; Porzio, M. 1995. Encapsulation system for flavors and colors. En: Food Technology. 49 (5):76-82

Ré, M. 1998. Microencapsulation by spray drying. En: Drying Technology. 16 (6):1195-1236

Varshosaz, J.; Alinagari, R. 2005. Effect of citric acid as cross-linking agent on insulin loaded chitosan microspheres. En: Iranian Polymer Journal. 14 (7):647-656

Yañez Fernández, J.; Salazar Montoya, J.A.; Chaires Martínez, L.; Jiménez Hernández, J.; Márquez Robles, M.; Ramos Ramírez, E.G. 2002. Aplicaciones biotecnológicas de la microencapsulación. En: Avance y Perspectiva. (21):313 - 319 